\title{
Motivation for Sport: The Cognitive Orientation
}

\author{
Muhammad Badarnee1, Baraa Aslih', Smadar Goldman'², Shulamith Kreitler ${ }^{1 *}$ \\ ${ }^{1}$ School of Psychological Sciences, Tel Aviv University, Tel Aviv, Israel \\ ${ }^{2}$ Studio Bazel, Tel-Aviv, Israel \\ Email: mbdarnee@gmail.com, baraaaslih@mail.tau.ac.il,smadgold@gmail.com, ^shulamithkreitler@gmail.com
}

How to cite this paper: Badarnee, M., Aslih, B., Goldman, S., \& Kreitler, S. (2020). Motivation for Sport: The Cognitive Orientation. Psychology, 11, 1559-1573. https://doi.org/10.4236/psych.2020.1110099

Received: September 21, 2020

Accepted: October 26, 2020

Published: October 29, 2020

Copyright (C) 2020 by author(s) and Scientific Research Publishing Inc. This work is licensed under the Creative Commons Attribution International License (CC BY 4.0).

http://creativecommons.org/licenses/by/4.0/ (c) (i) Open Access

\begin{abstract}
The major problems identified in the assessment of motivation for sport are using questionnaires with multiple scales whose results shift across contexts, adding to the predictions variables of other psychological factors, and especially replacing actual behavior assessments by intents to participate in sport and self-reports which do not represent behavior. The cognitive orientation approach to motivation enables prediction of actual behavior by assessing the following four types of beliefs: about oneself, others and reality, norms and goals. It was hypothesized that intents and self-reports of sport behavior are related only to one belief type, which is beliefs about oneself. The underlying assumption was that individuals engaged in sport experience a kind of commitment to the action they do so that they may try to bring their beliefs about self in concordance with the behavior. Two samples were used: a Jewish one $(\mathrm{n}=148)$ and an Arab one $(\mathrm{n}=319)$. The participants responded to a demographic questionnaire, a questionnaire describing their physical activity and a cognitive orientation questionnaire of motivation for sport which assessed four belief types. Regression analyses of the four belief types as predictors of sport activity showed that in both samples as hypothesized only beliefs about self had a significant contribution. The implications in regard to assessing motivation for sport and training are discussed.
\end{abstract}

\section{Keywords}

Motivation for Sport, Cognitive Orientation, Self Beliefs, Commitment

\section{Introduction}

The great importance of sport in regard to mental and physical health has caused a lot of research about motivation for sport, both in order to motivate more individuals to participate in it and to reduce dropout rates that may be quite high or keep them low (Butcher, Lindner, Koenraad, \& David, 2002; Crane 
\& Temple, 2014; Latorre-Román, Pinillos, \& Robles, 2018). Motivation for sport seems to be a complex issue considering the variety of populations that engage in it (e.g. children, adolescents, elderly), the reasons for doing it (e.g. fitness, weight control, competition), the different sport activities (e.g. baseball, swimming) and the different contexts (e.g. entertainment, clubs, educational frameworks). This situation is reflected also in the scales developed for assessing motivation for sport. Most of the scales include several components (Clancy, Herring, \& Clampbell, 2017). For example, the Sport Motivation Scale includes three types of intrinsic motivation: to know, to accomplish things and experience stimulation; three forms of regulation for external motivation: identified, introjected and external, complemented by a seventh component of amotivation which represents helplessness (Pelletier et al., 1995). In the scale Intrinsic Motivation Inventory (McAuley et al., 1989) the major components are interest/enjoyment, perceived competence, effort, value/usefulness, felt pressure/tension, perceived choice, and relatedness. In the Task and Ego Orientation in Sport Questionnaire the major components are task orientation and ego orientation (Duda \& Whitehead, 1998). Another set of intrinsic-extrinsic motivation factors includes social reinforcement, fringe benefits, fame and fortune, external forces, proving oneself, social benefits, mental enrichment, expression of self, sense of accomplishment, and self-enhancement (Pedersen, 2002). The problem with scales of this kind is that the results may be equivocal. The components that turn out to have significant correlates may differ in different samples or in regard to different kinds of sport (e.g. Cece, Lienhart, Nicaise, Guillet-Descas, \& Martinent, 2019; Li, Chi, Yeh, Guo, Ou, \& Kao, 2011; Memon, Memon, Ahmed, \& Ferroy, 2018; Tóth-Király, Amoura, Bőthe, Orosz, \& Rigó, 2020; Zahariadis, Tsorbatzoudis, \& Alexandris, 2006). For example, a study which used both the Sport Motivation Scale and the Task and Ego Orientation in Sport Questionnaire, showed that non-competitive athletes had higher levels of introjected regulation (extrinsic motivation), amotivation and lower levels of ego orientation, whereas rhythmic gymnastics scored high in task orientation, and task orientation was positively related to high levels of intrinsic motivation regardless of the levels of ego orientation (Koumpoula, Tsopani, Flessas, \& Chairopoulou, 2011). Results of this kind do not enable to conclude of which the factors of motivation are related to sport activity and not even about whether the assessed motivation contributes to the activity.

Another theoretically difficult issue concerning the studies on sport motivation is that psychological variables other than motivation are added as external props to the prediction without being integrated into the motivation construct, for example, achievement goals in addition to intrinsic motivation ( $\mathrm{Li}$ et al., 2011), global need fulfillment, autonomy satisfaction, relatedness, and competence frustration (Tóth-Király et al., 2020), motives like appearance/weight or health/fitness as well as personality traits like neuroticism and openness (Ingledew \& Markland, 2008).

Finally, the most problematic issue concerning the assessment of motivation 
for sport concerns the correlate or dependent variable of motivation. In the majority of studies actual participation in sport is not assessed but rather different variables that are not behavior, such as enjoyment or perceived competence (Gardner, Magee, \& Vella, 2017; Pelletier et al., 1995). The two variables closest to behavior that are used in studies on motivation for sport are intent to participate or self reports of behavior.

The intent to participate in sport activity is a variable that appears in many studies replacing the assessment of actual behavior (e.g. Chan et al., 2015; Gardner, Magee, \& Vella, 2017; Vlachopoulos, Karageorghis, \& Terry, 2000). There is no theoretical or empirical evidence that intention to do something and actual behavior are identical and can replace each other. The intention-behavior gap has been well-known for many decades and has been reported in a great many different domains, most often in regard to the intent to engage in physical activity rather than assessing the actual performance of physical activity (Maher et al., 2017; Rebar, Rhodes, \& Gardner, 2019; Vallerand, Rhodes, Walker, \& Courneya, 2016) and food and dieting (Reichenberger, Smyth, Kuppens, \& Blechert, 2019; Larsen et al., 2018). There is also no theoretical basis to expect a relation between intents and behavior because intent is not a necessary prerequisite of behavior and additionally it is conscious and based on considerations that do not necessarily precede most behaviors.

The other variable that replaces behavior in the studies on motivation for sport is self-reports of behavior (e.g. Cece, Lienhart, Nicaise, Guillet-Desca, \& Martinent, 2018; Ferrari et al., 2020; Tsorbatzoudis, Alexandris, Zahariadis, \& Grouios, 2006). This variable too has been shown in many studies to be unrelated to behavior in regard to physical activity (Colley et al., 2019), as well as other behaviors, e.g. aggression (Poltavski, Van Eck, Winger, \& Honts, 2018) or use of smartphone (Yook, Park, Choi, Kim, \& Choi, 2019). Again, there is no theoretical reason to expect behavior and self-report of behavior to be closely related because each has a different psychological role and depends on a different set of correlates.

The present study is designed to shed some light on the relation between motivation for sport and behavior. The theoretical framework that we used for this purpose was the cognitive orientation (CO) approach which assesses motivation in terms of a motivational disposition that refers to four types of beliefs: beliefs about self, which describe different habits, facts, traits and features of the subject (e.g. I like good food; I was born in Jerusalem); general beliefs, which describe situations, attitudes and features referring to reality and other people (e.g. Paris is the capital of France; Lying never ends well); beliefs about standards and norms, which describe rules and standards based on ethical, functional or other bases (e.g. This application should be operated by pressing X; One should avoid hurting others); and beliefs about goals and wishes, which describe situations, events, objects, and features that describe things one would like or not like to have or be (e.g. I would like to be appreciated by many people) (Kreitler, 2004; Kreitler \& Kreitler, 1976, 1982, 2014). The beliefs do not refer to the behavior in 
question but represent its underlying meanings identified by a standard interviewing process of pretest subjects (Kreitler, 2004; Kreitler \& Kreitler, 1976, 1982, 2014).

The advantages of the $\mathrm{CO}$ approach are that it is specifically designed to predict actual behavior, is not subject to social desirability, is not based on ratioanl decision making and has a broad empirical basis of behavior predictions (e.g. Kreitler \& Kreitler, 1991, 2014; Kreitler, Kreitler, Len, Alkalay, \& Barak, 2008).

In the present study the $\mathrm{CO}$ approach is applied in order to shed light on the relation between the $\mathrm{CO}$ scores and self-reported behavior. Our hypothesis was that self-reported behavior would be related only to beliefs about self. Three considerations led to this hypothesis. The first was that since self-reported behavior is not identical to behavior it would be related to fewer than to four belief types (see demonstration by Azuri, Tabak, \& Kreitler, 2013). Secondly, we assumed that self-reported behavior implies involvement in a process of change that is oriented towards engaging in sport in the future. In terms of the Stages of Change Model (Prochaska \& DiClemente, 1984) the individual may be described as proceeding along the stages from precontemplation, and contemplation through preparation and action to maintenance and termination. Since in self-reported behavior the individual refers to behavior, it is likely that the individual is in the action stage in which a certain change of behavior has occurred but it is not yet well ingrained and may be affected by beliefs (Baranowski, 1992). Finally, the third assumption was that the very act of dealing with sport involves some kind of commitment on the part of the of the individual which often leads to an attempt to bring one's beliefs about oneself in accord with one's behavior so as to appear consistent as required by one's personal and socially accepted norms (Cialdini, 2001; Abrahamse, Steg, Vlek, \& Rottengatter, 2005; Burger \& Guadagno, 2003; Kerr, Garst, Lewandowski, \& Harris, 1997; Lokhorst, Werner, Staats, van Dijk, \& Gale, 2013). These considerations supported the hypothesis that self-reported behavior would be correlated with self beliefs in the $\mathrm{CO}$ questionnaire.

\section{Method}

\subsection{Participants}

There were two samples: one of Jewish participants $(\mathrm{n}=148)$, and one of Arab participants $(n=319)$. In view of the evidence that sport plays a role in regard to national self identities (Schinke \& Hanrahan, 2009), we expected a possible effect of ethnic background also on self beliefs. Therefore, we included in the study two separate samples-Arab and Jewish-in order to control for the impact of ethnic background on the relation of self beliefs to sport activities. The information about the gender distribution, age, education, marital status and engaging in physical activity is presented in Table 1 . Table 1 shows that the samples are similar in the large range of ages they include which indicates that the participants have not been preselected. Further, the samples are also similar in the percentages of married individuals and those with academic background. However they 
Table 1. Background information about the participants in the two samples.

\begin{tabular}{|c|c|c|}
\hline Variable & Jewish sample & Arab sample \\
\hline Total number & 148 & 319 \\
\hline Gender & 89 men, 59 women & 105 men, 214 women \\
\hline Age & $\begin{array}{l}\text { Mean } 33.35, \mathrm{SD}=6.9 \\
\quad \text { Range: } 18-89\end{array}$ & $\begin{array}{c}\text { Mean } 27.92, \mathrm{SD}=7.61 \\
\text { Range: } 17-92\end{array}$ \\
\hline Marital status & $\begin{array}{c}\text { Unmarried } 60.4 \% \text {; married or with } \\
\text { partner } 34.9 \% \text {; divorced } 4 \%\end{array}$ & $\begin{array}{c}\text { Unmarried } 59.2 \% \text {; married or with } \\
\text { partner } 38.5 \% \text {; divorced } 2.2 \%\end{array}$ \\
\hline Education & Academic education $85.2 \%$ & Academic education $86.5 \%$ \\
\hline Number of children & $\begin{array}{c}\text { 0ne child } 6.7 \% \text {; two children } 11.4 \% \text {; } \\
\text { three children or more } 2.7 \%\end{array}$ & $\begin{array}{c}\text { One child } 5.9 \% \text {; two children } 6.5 \% \text {; } \\
\text { three children or more } 12.2 \%\end{array}$ \\
\hline Physical activity: Frequency & $\begin{array}{c}\text { Once a week } 11.4 \% ; 2 \text { times a week } \\
40.3 \% ; 3 \text { - } 4 \text { times a week } 29.5 \% \text {; } \\
\text { over } 5 \text { time a week } 13.4 \%\end{array}$ & $\begin{array}{l}\text { Once a week } 4.3 \% ; 2 \text { times a week } \\
9.4 \% ; 2 \text { - } 4 \text { times a week } 15.3 \% \\
\text { over } 5 \text { times a week } 5.9 \%\end{array}$ \\
\hline Physical activity: Duration & $77.1 \%$ at least 2 years & $26.3 \%$ at least 2 years \\
\hline
\end{tabular}

differ in the extent to which the individuals are involved in physical activity, whcih provides a challenging platform for testing the hypotheses of the study. In addition, the samples differ in the number of children which is higher in the Arab sample. This variable turned out to be important in affecting reported physical activity (see Results).

\subsection{Materials and Procedure}

The participants were administered three questionnaires. One referred to background information about gender, age, education, marital status, and number of children. The second referred to physical activity and included questions about kinds of activities, frequency of training per week, duration of trainings, importance, effort, enjoyment, steadiness, framework in which the activity took place, and duration. All responses were in the form of checking one of the presented alternatives. The third questionnaire was the cognitive orientation of sport activity (Raviv \& Kreitler, 2001) that was designed to assess the motivation for sport activity. It included four parts, one referring to beliefs about self, one to general beliefs, one to beliefs about norms and one to beliefs about goals, each preceded by a description of the kind of items in that part, e.g. referring to norms or goals. Each of the parts included 13 statements, with response alternatives ranging from "very true" to "not at all true", scores 4 to 1 , respectively. Some of the statements underwent recoding so that all were oriented in the direction of supporting physical activity. The statements in each part referred to the following 13 themes: 1) Belongingness; 2) Rivalry; 3) External appearance; 4) Reduced stress; 5) Social evaluation; 6) Health; 7) Flexibility; 8) Weight; 9) Perfection; 10) Strength; 11) Enjoyment; 12) Feeling one's body; 13) Perseverance.

The major scores of the questionnaire are the sums of the four belief types that represent the degree of support of the beliefs for the specific behavior. The beha- 
vior in question is expected to occur when at least three of the belief types support the behavior. Secondary scores of the questionnaire represent the themes-or factors representing the themes-that provide information about the contents of the beliefs orienting toward the behavior in question. Notably, the different themes are summed up in the overall score of the CO questionnaire rather than functioning as separate scales

The questionnaires were distributed via social media for a predetermined period of time of three months. Participants entered a link they saw in posts on social media platforms. They were asked to take part in a study on motivation for physical activity and were informed that their personal details would remain completely anonymous. About $1 \%$ of the submitted questionnaires were removed from the file due to incomplete responses. Both studies got the permission of the ethics committee in the university.

\section{Results}

\subsection{Factor Analysis of Physical Activity Responses}

The different responses in the questionnaire in regard to engaging in physical activity were factor analyzed, separately in the two samples. Table 2(a) and Table 2 (b) present the findings. In both samples all the items of engaging in sport

Table 2. (a) Factor analysis of the extent of engaging in sport activity in the Jewish sample; (b) Factor analysis of the extent of engaging in sport activity in the Arab sample.

(a)

\begin{tabular}{cc} 
Sport activity & Factor Loadings \\
\hline It is important to do sport & .81 \\
Frequency of activity in a week & .75 \\
Duration of the exercise in hours & .62 \\
Effort & .45 \\
Enjoyment & .72 \\
Duration of working out in years & .76 \\
Eigenvalue & 2.76 \\
of Total Variance & 48.44 \\
\hline
\end{tabular}

(b)

\begin{tabular}{cc}
\hline Sport activity & Factor Loadings \\
\hline It is important to do sport & .50 \\
Frequency of activity in a week & .72 \\
Duration of the exercise in hours & .48 \\
Effort & .70 \\
Enjoyment during the workout & .60 \\
How long do you workout (in years) & .46 \\
Eigenvalue & 2.06 \\
$\%$ of Total Variance & 34.31 \\
\hline
\end{tabular}


were loaded on one factor which accounted in the Jewish sample for $48.44 \%$ of the variance and in the Arab sample only for $34.31 \%$. The two samples differed also in the items with the highest loadings. In the Jewish sample, the items with the highest loadings were importance of sports, weekly frequency of training and long-term duration of training. In the Arab sample, the items with the highest loading were weekly frequency of training, invested effort and enjoyment. The results indicate that the physical activity factors in the two samples differ in the total variance they account for and in the relative loadings of the items defining the factors. These items indicate an impersonal approach in the Jewish sample and a more personal approach in the Arab sample.

\subsection{The Four Belief Types and Themes in the Jewish and Arab Samples}

Table 3 shows the means, SDs and reliability coefficients of the four belief types in the two samples. The results indicate that in each of the belief types the mean in the Jewish sample is significantly lower than in the Arab sample. The reliability coefficients are in the acceptable range and similar for the two samples.

The 13 themes of the CO questionnaire were submitted to factor analysis in the two samples separately. The results are presented in Table 4(a) and Table 4(b). The results show that the themes formed three factors in the Jewish sample (accounting for $52.61 \%$ of the variance) and two factors in the Arab sample (accounting for $39.92 \%$ of the variance). The three factors in the Jewish sample may be identified as representing bodily external appearance (loaded themes: perfection, external appearance, feeling the body), social belongingness (loaded themes: belongingness, social evaluation), and physical state (loaded themes: reduced stress, strength), respectively. The two factors in the Arab sample may be identified as representing bodily experience (loaded themes: enjoyment, feeling the body, flexibility, weight) and social status (loaded themes: social evaluation, external appearance, strength). Notably, even when the factors in the two samples seem similar, the themes loaded on them differ, as in regard to the second factor in the two samples which is socially oriented: in the Jewish sample the emphasis is on belongingness, whereas in the Arab sample it is rather on status.

Table 3. Means and standard deviations of the four belief types of the cognitive orientation questionnaire of sport in the Jewish and Arab samples.

\begin{tabular}{|c|c|c|c|c|c|c|c|}
\hline & \multicolumn{2}{|c|}{ Jewish sample $(n=148)$} & \multirow{2}{*}{$\begin{array}{c}\text { Reliab. } \\
\text { Alpha } \\
\text { Cronbach }\end{array}$} & \multicolumn{2}{|c|}{ Arab sample $(\mathrm{n}=305)$} & \multirow{2}{*}{$\begin{array}{l}\text { Reliab. } \\
\text { Alpha } \\
\text { Cronbach }\end{array}$} & \multirow{2}{*}{$t(d f)$} \\
\hline & $M$ & $S D$ & & $M$ & $S D$ & & \\
\hline Self & 2.04 & .33 & .63 & 2.79 & .31 & .62 & $23.52(451)^{\star * *}$ \\
\hline General & 2.02 & .26 & .63 & 2.93 & .25 & .63 & $35.21(429)^{\star * *}$ \\
\hline Norms & 2.26 & .33 & .71 & 2.84 & .37 & .72 & $15.57(408)^{\star * *}$ \\
\hline Goals & 2.01 & .38 & .79 & 2.89 & .40 & .70 & $21.03(389)^{\star * *}$ \\
\hline
\end{tabular}

${ }^{* * *} p<.001$. 
Table 4. (a) Factor analysis of the themes of the CO questionnaire of sport in the Jewish sample; (b) Factor analysis of the themes of the CO questionnaire of sport in the Arab sample.

(a)

\begin{tabular}{|c|c|c|c|}
\hline \multicolumn{4}{|c|}{ Loadings } \\
\hline Theme number & Factor 1 & Factor 2 & Factor 3 \\
\hline T9 & .71 & & \\
\hline $\mathrm{T} 3$ & .70 & & \\
\hline T12 & .67 & & \\
\hline $\mathrm{T} 11$ & .65 & & \\
\hline $\mathrm{T} 13$ & .62 & & \\
\hline $\mathrm{T} 2$ & .58 & & \\
\hline $\mathrm{T} 8$ & & -.61 & \\
\hline T5 & & .58 & \\
\hline $\mathrm{T} 1$ & & .52 & \\
\hline T6 & & .40 & \\
\hline T7 & & & -.55 \\
\hline $\mathrm{T} 4$ & & & .47 \\
\hline $\mathrm{T} 10$ & & & .45 \\
\hline Eigenvalue & 3.81 & 1.79 & 1.24 \\
\hline$\%$ of Total Variance & 29.31 & 13.77 & 9.56 \\
\hline Total Variance & 52.64 & & \\
\hline
\end{tabular}

(b)

\begin{tabular}{ccc}
\hline Theme number & Factor 1 & Factor 2 \\
\hline $\mathrm{T} 13$ & .65 & \\
$\mathrm{~T} 11$ & .64 & \\
$\mathrm{~T} 12$ & .63 & \\
$\mathrm{~T} 7$ & .59 & \\
$\mathrm{~T} 8$ & .56 & \\
$\mathrm{~T} 9$ & .54 & \\
$\mathrm{~T} 1$ & .50 & .72 \\
$\mathrm{~T} 6$ & .36 & .58 \\
$\mathrm{~T} 5$ & & .50 \\
$\mathrm{~T} 3$ & & -.46 \\
$\mathrm{~T} 10$ & & -.45 \\
$\mathrm{~T} 4$ & & 2.03 \\
$\mathrm{~T} 2$ & 3.16 & 15.63 \\
Eigenvalue & 24.29 & \\
\% & & \\
Total Variance & 39.92 &
\end{tabular}

Note. The themes: 1) Belongingness; 2) Rivalry; 3) External appearance; 4) Reduced stress; 5) Social evaluation; 6) Health; 7) Flexibility; 8) Weight; 9) Perfection; 10) Strength; 11) Enjoyment; 12) Feeling one's body; 13) Perseverance. 


\subsection{Regression Analyses of the CO Belief Types and Themes in Regard to Engaging in Physical Activity}

The predictive power of the belief types in regard to the variable of physical activity was assessed in the two samples separately and in terms of two regression analyses. One regression included only the four belief types as predictors, whereas the second regression analysis included in addition also the demographic variables of gender, age, marital status, number of children and education.

The regression analysis based only on the four belief types as predictors was similar in the major findings in the two samples. The regression analysis in the Jewish sample (Table 5(a)) showed that the only belief type that had a significant contribution to the dependent variable of physical activity was beliefs about self. General beliefs had a very marginal contribution in terms of significance ( $p$ $=.08$ ). The whole model proved significant and accounted for $34 \%$ of the variance. In the Arab sample too (Table 5(b)) the only belief type with a significant contribution to the dependent variable of physical activity was beliefs about self. Again, the whole model was significant and accounted for $35 \%$ of the variance.

The regression analyses based on adding to the belief types the demographic variables showed no differences in the Arab sample (Table 6(b)). The only belief type with a significant contribution to the prediction was beliefs about self. In the Jewish sample there were some differences compared with the regression without the demographic variables (Table 6(a)). Insofar as the belief types are concerned, again beliefs about self was the only belief type with a significant

Table 5. (a) Regression analysis of the four types of beliefs as predictors and physical activity as the dependent variable in the Jewish sample; (b) Regression analysis of the four types of beliefs as predictors and physical activity as the dependent variable in the Arab sample.

(a)

\begin{tabular}{ccccc}
\hline & B & Beta & T & $p$ \\
\hline Self & 1.64 & .53 & 6.91 & .00 \\
General & .533 & .14 & 1.77 & .08 \\
Norms & .04 & .01 & .18 & .86 \\
Goals & .28 & .11 & 1.44 & .15 \\
\hline
\end{tabular}

$\mathrm{F}(4,129)=16.63, p<.000$, with $\mathrm{R}^{2}$ of .34.

(b)

\begin{tabular}{ccccc}
\hline & B & Beta & T & $p$ \\
\hline Self & 1.78 & .51 & 4.85 & .00 \\
General & .76 & .15 & 1.44 & .15 \\
Norms & -.20 & -.08 & -.66 & .51 \\
Goals & .14 & .06 & .53 & .60 \\
\hline
\end{tabular}

$\mathrm{F}(4,86)=11.72, p<.000$, with $\mathrm{R}^{2}$ of .35 . 
Table 6. (a) The regression analysis of the four belief types, gender, age, marital status, number of children and education as predictors and physical activity as the dependent variable in the Jewish sample; (b) The regression analysis of the four belief types, gender, age, marital status, number of children and education as predictors and physical activity as the dependent variable in the Arab sample.

(a)

\begin{tabular}{ccccc}
\hline & B & Beta & T & $p$ \\
\hline Gender & .27 & .13 & 1.68 & .10 \\
Age & .05 & .04 & .51 & .61 \\
Marital status & -.10 & -.06 & -.70 & .49 \\
Number of children & -.31 & -.27 & -2.98 & .00 \\
Education & .05 & .03 & .37 & .71 \\
Self & 1.68 & .54 & 7.09 & .00 \\
General & .54 & .14 & 1.76 & .08 \\
Norms & .02 & .01 & .10 & .92 \\
Goals & .37 & .14 & 1.91 & .06 \\
\hline
\end{tabular}

$\mathrm{F}(9,123)=9.45, p<.000$, with $\mathrm{R}^{2}$ of .41.

(b)

\begin{tabular}{ccccc}
\hline & B & Beta & T & $p$ \\
\hline Gender & .06 & .03 & .29 & .77 \\
Age & .01 & .09 & .65 & .52 \\
Marital status & -.22 & -.11 & -.92 & .36 \\
Number of children & .02 & .02 & .12 & .90 \\
Education/work & .09 & .06 & .50 & .55 \\
Self & 1.76 & .51 & 4.62 & .00 \\
General & .79 & .16 & 1.42 & .16 \\
Norms & -.16 & -.06 & -.45 & .66 \\
Goals & .12 & .05 & .42 & .68 \\
\hline
\end{tabular}

$\mathrm{F}(9,81)=5.17, p<.000$, with $\mathrm{R}^{2}$ of .37.

contribution. Contributions with marginal contributions in terms of significance were general beliefs $(p=.08)$ and goal beliefs $(p=.06)$. The whole model was significant and accounted for $41 \%$ of the variance as compared to $34 \%$ without the demographic variables. The difference is due to the significant contribution of the variable of number of children: a higher number reduces physical activity of the parents (Table 7).

Another regression analysis was done with the factors representing the themes as predictors of physical activity. In both samples the whole model was significant but the extent of the variance accounted for was low (15\% in the Jewish sample and $20 \%$ in the Arab sample). In the Jewish sample the significant contributions were for the first factor of bodily external appearance and the third 
Table 7. (a) Regression analysis of the three theme factors as predictors and physical activity as the dependent variable in the Jewish sample; (b) Regression analysis of the two theme factors as predictors and physical activity as the dependent variable in the Arab sample.

(a)

\begin{tabular}{ccccc}
\hline Independent variable & $B$ & Beta & $T$ & $p$ \\
\hline Factor 1 & -.31 & -.31 & -3.92 & .00 \\
Factor 2 & .11 & .11 & 1.41 & .16 \\
Factor 3 & .20 & .21 & 2.60 & .01 \\
\hline
\end{tabular}

$\mathrm{F}(3,136)=8.11, p<.000$, with $\mathrm{R}^{2}$ of .15 .

(b)

\begin{tabular}{ccccc}
\hline Independent variable & $B$ & Beta & $t$ & $p$ \\
\hline Factor 1 & .42 & .43 & 4.86 & .000 \\
Factor 2 & -.19 & -.18 & -1.98 & .05 \\
\hline
\end{tabular}

$\mathrm{F}(2,102)=12.68, p<.000$, with $\mathrm{R}^{2}$ of .20 .

representing physical state, whereby the former had a negative contribution and the latter a positive one to physical activity. In the Arab sample both factors-focused on the body and on social status-had significant contributions, the former positive and the latter negative.

\section{Discussion}

The findings provide full support to the major hypothesis of the study which was that self-reported physical activity would be predicted only by one belief type and that this belief type would be beliefs about self. Notably, this exact finding was obtained in the two samples that differed in ethnic background of the respondents, in the factorial composition of the predicted variable of physical activity, in the factorial structure of the themes of the $\mathrm{CO}$ questionnaire, and in the mean values of the four belief types. These differences between the samples provide extra support to the evidence for the tested hypothesis underscoring its sturdiness.

The major finding of the study has several implications. The major one is that self-reported behavior is not identical to actual behavior of physical activity as shown by the fact that it is related only to one belief type. Hence, it is advisable to base the assessment of physical activity on information that is not limited to self-reported behavior. It may still be self-reported but should refer to correlates or variables whose veridicality is not susceptible to doubt.

The evidence about the relation of beliefs about self to the self-reported behavior suggests that beliefs about self may be used as a starting point for promoting engagement in physical activity. The suggested act of promoting the behavior of physical activity should be based on strengthening specific belief types so that they join beliefs about self and form the cluster of beliefs, which constitutes the vector orienting towards behavior. The findings in the Jewish sample indicate 
which types of beliefs are likely to contribute to promoting physical activity if they are strengthened so that they support the indicated direction. These are general beliefs and goal beliefs that turned out to have marginal contributions to the prediction. There is a systematic procedure for strengthening belief types by engaging the interest and promoting cognitive elaboration of the participants in the indicated direction (Kreitler \& Kreitler, 2014). Notably, our suggestion based on the findings of the study is contrary to the conventional kind of instruction for motivating physical activity that is based on norm beliefs; i.e. one should engage in sport to improve one's health etc. Norm beliefs are the only type of belief out of the four that had no contribution whatsoever to predicting physical activity in any of the two samples.

The differences between the samples in the factorial structures of physical activity and of the themes of the CO questionnaire indicate that both in assessment and in training for promoting physical activity it is of great importance to consider the ethnic background of the participants. The implications of our study are that in promoting physical activity in the Jewish samples it is advisable to assume an impersonal attitude to the act of sport, emphasizing its importance and the temporal duration of the activity and its benefits in terms of physical state. In the Arab samples it is advisable to emphasize the more personal aspects of enjoyment and invested effort in the activity and its benefits in terms of bodily experience.

\section{Declaration}

The study is based on data collected by the second and third authors in the framework of their seminar papers in the course of their studies, under the supervision of Professor Shulamith Kreitler.

\section{Conflicts of Interest}

The authors declare no conflicts of interest regarding the publication of this paper.

\section{References}

Abrahamse, W., Steg, L., Vlek, C., \& Rottengatter, T. (2005). A Review of Intervention Studies Aimed at Household Energy Conservation. Journal of Environmental Psychology, 25, 273-291. https://doi.org/10.1016/j.jenvp.2005.08.002

Azuri, P., Tabak, N., \& Kreitler, S. (2013). Contact between Organ Recipients and Donor Families Applying the Cognitive Orientation Theory. Progress in Transplantation, 23, 342-349. https://doi.org/10.7182/pit2013708

Baranowski, T. (1992). Beliefs as Motivational Influences at Stages in Behavior Change. International Quarterly of Community Health Education, 13, 3-29. https://doi.org/10.2190/W2RA-9LTF-D84U-FNHA

Burger, J. M., \& Guadagno, R. E. (2003). Self-Concept Clarity and the Foot-in-the-Door Procedure. Basic and Applied Social Psychology, 25, 79-86.

https://doi.org/10.1207/S15324834BASP2501_6 
Butcher, J., Lindner, K. J., \& Johns, D. P. (2002). Withdrawal from Competitive Youth Sport: A Retrospective Ten-Year Study. Journal of Sport Behavior, 25, 145-163.

Cece, V., Lienhart, N., Nicaise, V., Guillet-Descas, E., \& Martinent, G. (2018). Longitudinal Sport Motivation among Young Athletes in Intensive Training Settings: The Role of Basic Psychological Needs Satisfaction and Thwarting in the Profiles of Motivation. Journal of Sport and Exercise Psychology, 40, 186-195. https://doi.org/10.1123/jsep.2017-0195

Cece, V., Lienhart, N., Nicaise, V., Guillet-Descas, E., \& Martinent, G. (2019). Changes Longitudinal Sport Motivation among Young Athletes in Intensive Training Settings: Using Methodological Advances to Explore Temporal Structure of Youth Behavioral Regulation in Sport Questionnaire Scores. Journal of Sport \& Exercise Psychology, 41, 24-35. https://doi.org/10.1123/jsep.2017-0194

Chan, D. K., Dimmock, J. A., Donovan, R. J., Hardcastle, S., Lentillon-Kaestner, V., \& Hagger, M. S. (2015). Self-Determined Motivation in Sport Predicts Anti-Doping Motivation and Intention: A Perspective from the Trans-Contextual Model. Journal of Science and Medicine in Sport, 18, 315-322. https://doi.org/10.1016/j.jsams.2014.04.001

Cialdini R. B. (2001). Influence: Science and Practice. Boston, MA: Allyn \& Bacon.

Clancy, R. B., Herring, M. P., \& Campbell, M. J. (2017). Motivation Measures in Sport: A Critical Review and Bibliometric Analysis. Frontiers in Psychology, 8, 348.

https://doi.org/10.3389/fpsyg.2017.00348

Colley, R. C., Butler, G., Garriguet, D., Prince, S. A., \& Roberts, K. C. (2019). Comparison of Self-Reported and Accelerometer-Measured Physical Activity among Canadian Youth. Health Reports, 30, 3-12.

Crane, J. R., \& Temple, V. A. (2014). Early Sport Dropout: High Performance in Early Years in Young Athletes Is Not Related with Later Success. European Physical Education Review, 21, 114-131. https://doi.org/10.1177/1356336X14555294

Duda, J. L., \& Whitehead, J. (1998). Measurement of Goal Perspectives in the Physical Domain. In J. Duda (Ed.), Advances in Sport and Exercise Psychology Measurement (pp. 21-48). Morgantown, WV: Fitness Information Technologies.

Ferrari, G. L. M., Kovalskys, I., Fisberg, M., Gómez, G., Rigotti, A., Sanabria, L. Y. C., García, M. C. Y., Torres, R. G. P., Herrera-Cuenca, M., Zimberg, I. Z., Guajardo, V., Pratt, M., Pires, C. A. M., Colley, R. C., Solé, D., \& ELANS Study Group (2020). Comparison of Self-Report versus Accelerometer-Measured Physical Activity and Sedentary Behaviors and Their Association with Body Composition in Latin American Countries. PLoS ONE, 15, e0232420. https://doi.org/10.1371/journal.pone.0232420

Gardner, L. A., Magee, C. A., \& Vella, S. A. (2017). Enjoyment and Behavioral Intention Predict Organized Youth Sport Participation and Dropout. Journal of Physical Activity and Health, 14, 861-865. https://doi.org/10.1123/jpah.2016-0572

Ingledew, D. K., \& Markland. D. (2008). The Role of Motives in Exercise Participation. Psychology and Health, 23, 807-828. https://doi.org/10.1080/08870440701405704

Kerr, N. L., Garst, J., Lewandowski, D. A., \& Harris, S. E. (1997). That Still, Small Voice: Commitment to Cooperate as an Internalized versus a Social Norm. Personality and Social Psychology Bulletin, 23, 1300-1311. https://doi.org/10.1177/01461672972312007

Koumpoula, M., Tsopani, D., Flessas, K., \& Chairopoulou, G. G. (2011). The Role of Motives in Exercise Participation. Psychology and Health, 23, 480-488.

Kreitler, H., \& Kreitler, S. (1976). Cognitive Orientation and Behavior. New York: Springer.

Kreitler, H., \& Kreitler, S. (1982). The Theory of Cognitive Orientation: Widening the 
Scope of Behavior Prediction. Progress in Experimental Personality Research, 11, 101-169. https://doi.org/10.1016/B978-0-12-541411-1.50009-0

Kreitler, S. (2004). The Cognitive Guidance of Behavior. In J. T. Jost, M. R. Banaji, \& D. A. Prentice (Eds.), Perspectivism in Social Psychology: The Yin and Yang of scientific progress (pp. 113-126). Washington DC: American Psychological Association. https://doi.org/10.1037/10750-009

Kreitler, S., \& Kreitler, H. (1991). Cognitive Orientation and Physical Disease or Health. European Journal of Personality, 5, 109-129. https://doi.org/10.1002/per.2410050205

Kreitler, S., \& Kreitler, M. M. (2014). Changing Attitudes and Beliefs. In C. Pracana (Ed.), International Psychological Applications Conference and Trends (InPact) (pp. 99-102). Lisbon, Portugal: World Institute for Advanced Research and Science (WIARS).

Kreitler, S., Kreitler, M. M., Len, A., Alkalay, Y., \& Barak, F. (2008). Psychological Risk Factors for Colorectal Cancer? Psycho-Oncologie, 2, 131-145.

https://doi.org/10.1007/s11839-008-0094-9

Larsen, J. K., Hermans, R. C. J., Sleddens, E. F. C., Vink, J. M., Kremers, S. P. J., Ruiter, E. L. M., \& Fisher, J. O. (2018). How to Bridge the Intention-Behavior Gap in Food Parenting: Automatic Constructs and Underlying Techniques. Appetite, 123, 191-200. https://doi.org/10.1016/j.appet.2017.12.016

Latorre-Román, A., Pinillos, F. G., \& Robles, J. L. (2018). Early Sport Dropout: High Performance in Early Years in Young Athletes Is Not Related with Later Success. Retos, 33, 210-212. https://doi.org/10.47197/retos.v0i33.58225

Li, C. H., Chi, L., Yeh, S. R., Guo, K. B., Ou, C. T., \& Kao, C. C. (2011). Prediction of Intrinsic Motivation and Sports Performance Using $2 \times 2$ Achievement Goal Framework. Psychological Reports, 108, 625-637. https://doi.org/10.2466/05.11.14.PR0.108.2.625-637

Lokhorst, A. M., Werner, C., Staats, H., van Dijk, E., \& Gale, J. L. (2013). Commitment and Behavior Change: A Meta-Analysis and Critical Review of Commitment-Making Strategies in Environmental Research. Environment and Behavior, 45, 3-34. https://doi.org/10.1177/0013916511411477

Maher, J. P., Rhodes, R. E., Dzubur, E., Huh, J., Intille, S., \& Dunton, G. F. (2017). Physical Activity Intention-Behavior Coupling in Adults. Translational Behavioral Medicine, 7, 709-718. https://doi.org/10.1007/s13142-017-0472-6

McAuley, E., Duncan, T., \& Tammen, V. V. (1989). Psychometric Properties of the Intrinsic Motivation Inventory in a Competitive Sport Setting: A Confirmatory Factor Analysis. Research Quarterly for Exercise and Sport, 60, 48-58. https://doi.org/10.1080/02701367.1989.10607413

Memon, A. R., Memon, A. U. R., Ahmed, I., \& Feroz, J. (2018). Motivation and Factors Affecting Sports Participation: A Cross-Sectional Study on Female Medical Students in Pakistan. The Journal of the Pakistan Medical Association, 68, 1327-1333.

Pedersen, D. M. (2002). Intrinsic-Extrinsic Factors in Sport Motivation. Perceptual and Motor Skills, 95, 459-476. https://doi.org/10.2466/PMS.95.6.459-476

Pelletier, L. G., Fortier, M. S., Vallerand, R. J., Tuson, K. M., Briere, N. M., \& Blais, M. R. (1995). Toward a New Measure of Intrinsic Motivation, Extrinsic Motivation, and Amotivation in Sports: The Sport Motivation Scale (SMS). Journal of Sport Exercise Psychology, 17, 35-53. https://doi.org/10.1123/jsep.17.1.35

Poltavski, D., Van Eck, R., Winger, A. T., \& Honts, C. (2018). Using a Polygraph System for Evaluation of the Social Desirability Response Bias in Self-Report Measures of Aggression. Applied Psychophysiology and Biofeedback, 43, 309-318.

https://doi.org/10.1007/s10484-018-9414-4 
Prochaska, J. O., \& DiClemente, C. C. (1984). The Transtheoretical Approach: Crossing Traditional Boundaries of Therapy. Homewood, IL: Dow Jones-Irwin.

Raviv, S., \& Kreitler, S. (2001). The Nature and the Nurturing of Motivation to Engage in Sport According to the Cognitive Orientation Theory. Movement: Journal of Physical Education and Sport Sciences, 6, 6-31.

Rebar, A. L., Rhodes, R. E., \& Gardner, B. (2019). How We Are Misinterpreting Physical Activity Intention-Behavior Relations and What To Do about It. The International Journal of Behavioral Nutrition and Physical Activity, 16, Article No. 71. https://doi.org/10.1186/s12966-019-0829-y

Reichenberger, J., Smyth, J. M., Kuppens, P., \& Blechert, J. (2019). “I Will Fast... Tomorrow": Intentions to Restrict Eating and Actual Restriction in Daily Life and Their Person-Level Predictors. Appetite, 149, 10-18. https://doi.org/10.1016/j.appet.2019.04.019

Schinke, R. J., \& Hanrahan, S. J. (Eds.) (2009). Cultural Sport Psychology. Champaign, IL: Human Kinetics. https://doi.org/10.5040/9781492595366

Tóth-Király, I., Amoura, C., Bőthe, B., Orosz, G., \& Rigó, A. (2020). Predictors and Outcomes of Core and Peripheral Sport Motivation Profiles: A Person-Centered Study Journal of Sports Sciences, 38, 897-909. https://doi.org/10.1080/02640414.2020.1736765

Tsorbatzoudis, H., Alexandris, K., Zahariadis, P., \& Grouios, G. (2006). Examining the Relationship between Recreational Sport Participation and Intrinsic and Extrinsic Motivation and Amotivation. Perceptual and Motor Skills, 103, 363-374. https://doi.org/10.2466/pms.103.2.363-374

Vallerand, J. R., Rhodes, R. E., Walker, G. J., \& Courneya, K. S. (2016). Understanding Strength Exercise Intentions and Behavior in Hematologic Cancer Survivors: An Analysis of the Intention-Behavior Gap. Journal of Cancer Survivorship: Research and Practice, 10, 945-955. https://doi.org/10.1007/s11764-016-0540-9

Vlachopoulos, S. P., Karageorghis, C. I., \& Terry, P. C. (2000). Motivation Profiles in Sport: A Self-Determination Theory Perspective. Research Quarterly for Exercise and Sport, 71, 387-397. https://doi.org/10.1080/02701367.2000.10608921

Yook, I. H., Park, S. J., Choi, M. J., Kim, D. J., \& Choi, I. Y. (2019). Factors Affecting Smartphone Usage Self-Report Levels. Studies in Health Technology and Informatics, 264, 1937-1938.

Zahariadis, P., Tsorbatzoudis, H., \& Alexandris, K. (2006). Self-Determination in Sport Commitment. Perceptual and Motor Skills, 102, 405-420.

https://doi.org/10.2466/pms.102.2.405-420 